\title{
Measuring children activity repertoire: is the paediatric activity card sort a good tool for Brazilian therapists?
}

\author{
Tatiana Barcelos Pontes ${ }^{a}$, Bruna Mesquita Silva ${ }^{a}$, Jaqueline Gonçalves Sousa ${ }^{a}$, \\ Pedro Henrique Tavares Queiroz de Almeida ${ }^{a}$, Jane Davis ${ }^{b}$, Helene Polatajko ${ }^{\mathrm{b}}$

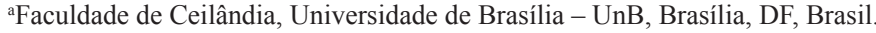 \\ ${ }^{b}$ Department of Occupational Science and Occupational Therapy, University of Toronto, Toronto, Canadá.
}

\begin{abstract}
Introduction: The primary Brazilian occupational therapists goal is to enable their clients to participate in the activities of everyday life. Thus, it is important that therapists have tools that capture their clients' activities repertoires. The Paediatric Activity Card Sort (PACS) is a client-centred tool designed to capture the activity repertoire of children. However, the PACS is based on the activities of Canadian children, leading to questions regarding its use in other countries. Objective: To determine the acceptability and applicability of the PACS with Brazilian children. Method: Sixty children between 5 and 14 years participated in a descriptive cross-sectional study. A questionnaire was used to gather sociodemographic information. Behavioural observations were used to judge the acceptability of the PACS. Item responses and their relation to sociodemographic variables were used to examine applicability. Descriptive statistics were used to describe demographics and item responses. Differences in the PACS scores between gender, race, presence of siblings, parents' educational levels and marital status were assessed using non-parametric statistics. Results: Reported participation in PACS activities ranged from 95.7\% (personal care) to $15.1 \%$ (sports). Eleven PACS activities had a participation rate of less than $10 \%$ and a number of new activities, not included in the PACS, were identified. Differences were found among gender and presence of siblings. Conclusion: With adjustments for the Brazilian context the PACS can be a useful tool to capture children activity suggesting the potential usefulness of a Brazilian PACS.
\end{abstract}

Keywords: Activity Pattern, Cross-cultural Comparison, Children, Adolescent.

\section{Medindo o repertório de atividades de crianças: paediatric activity card sort é uma boa ferramenta para terapeutas ocupacionais brasileiros?}

\begin{abstract}
Resumo: Introdução: A principal meta do terapeuta ocupacional, no Brasil, é habilitar o cliente para participar de atividades cotidianas significativas. Desta forma, é importante a utilização de avaliações que permitam conhecer o repertório de ocupações de seus clientes. A Paediatric Activity Card Sort (PACS) é uma avaliação centrada no cliente, desenvolvida para capturar o repertório de ocupações de crianças. Entretanto, a PACS é baseada em atividades típicas de crianças canadenses, gerando questionamentos sobre sua utilidade em outros países. Objetivo: Verificar a aceitação e a aplicabilidade da PACS com crianças brasileiras. Método: Sessenta crianças entre 5 e 14 anos de idade participaram de um estudo descritivo transversal. Os dados sociodemográficos foram coletados através de um questionário. Para verificar a aplicabilidade do PACS, foi usada a observação do comportamento. A associação entre a resposta aos itens da PACS e os dados sociodemográficos foi utilizada para analisar a aplicabilidade desta avaliação, através de análises descritivas. Diferenças nos escores da PACS em relação a sexo, raça, presença de irmãos, nível educacional dos pais e situação conjugal foram analisadas através de estatística não paramétrica.
\end{abstract}

Corresponding author: Tatiana Barcelos Pontes, Centro Metropolitano, conjunto A, lote 01, CEP 72220-900, Brasília, DF, Brasil, e-mail: tatianapontes@unb.br

Received on Nov. 19, 2015; $1^{\text {st }}$ Revision on Dec. 20, 2015; $2^{\text {nd }}$ Revision on Jan. 25, 2016; Accepted on Feb. $11,2016$. 
Resultados: A participação nas atividades da PACS variou de 95\% (cuidados pessoais) a 15\% (esportes). Onze atividades tiveram taxa de participação inferior a $10 \%$ e 22 atividades não descritas pelo instrumento foram identificadas. Foram observadas diferenças significativas entre os sexos e a presença de irmãos. Conclusão: A PACS é uma ferramenta útil para capturar o repertório de ocupações de crianças, apresentando potencial de uso para a população brasileira, realizadas as alterações necessárias.

Palavras-chave: Repertório de Ocupações, Comparação Transcultural, Crianças, Adolescentes.

\section{Introduction}

A primary goal of Brazilian occupational therapists is to enable their clients to participate in the activities of everyday life. Participation in the everyday activities of childhood is related to health and well-being (MANDICH; RODGER, 2006). According to the International Classification of Functioning, Disability and Health (WORLD..., 2001), participation is defined as the involvement in life situations and comprises nine domains: learning and applying knowledge; general tasks and demands; communication; mobility; self-care; domestic life; interpersonal interactions and relationships; major life areas and community, social and civic life. The strength of the effect of participation in activities on health is dependent on the relationship between the person, the activity, and the environment with an individualised balance in self-care, productivity, and leisure (LAW; STEINWENDER; LECLAIR, 1998), where activity is defined as a set of tasks with a specific end point or outcome that is greater than that any constituent task (POLATAJKO et al., 2004). Through participation in activities, children can learn new skills and develop meaningful relationships with others (WEISNER, 2002). Participation in activities contributes to children's physical, cognitive, social, and affective development (MANDICH; RODGER, 2006).

The nature of the activities in which children participate and the time use of children can vary around the world. Differences in participation in activities have been demonstrated in relation to age (LAW, 2002; DAVIS; POLATAJKO, 2006), sex (LARSON; VERMA, 1999; MOLINUEVO et al., 2010; CHEUNG, 2012), socioeconomic status (GONÇALVES et al., 2007; FREDRICKS; SIMPKINS, 2012), disabilities (TONKIN et al., 2014) and opportunity (WISEMAN; DAVIS; POLATAJKO, 2005; SHARP et al., 2015). Culture has also been found to relate to participation in occupation (LARSON; VERMA, 1999; GONÇALVES et al., 2007; SHIH; YI, 2014).

Although participation in occupation is related to health, well-being, learning, and thriving (JARUS et al., 2010), these concepts are not well recognized or explored, especially in South American countries, such as Brazil (GONÇALVES et al., 2007). A primary goal of Brazilian occupational therapists is to enable their clients to participate in the activities of everyday life. Accordingly it is important that therapists have measures that capture their clients' activity participation repertoires. The Paediatric Activity Card Sort (PACS), created in Canada, is one such measure. The purpose of the study reported here was to examine the usefulness of the PACS in the Brazilian context. The present study aims to contribute to the body of knowledge about children's activity participation repertoire.

\subsection{The PACS}

The Paediatric Activity Card Sort (PACS; MANDICH et al., 2004) was created in 2004 as a children's parallel to the Activity Card Sort (BAUM; EDWARDS, 2001), a client-centred, interview-based tool that measures changes in activity participation in older adults. The ACS has won broad acceptance and has been adapted and validated for use in several countries, such as Australia, Singapore, Israel and Hong Kong. The ACS has also been adapted for different age groups; in addition to the PACS which targets 5 to 14 year olds, versions also exist for adolescents and young adults, and preschool children.

The PACS examines children's activity patterns across a broad range of life activities. The authors of the PACS indicate that it has construct validity based on a comparative study with children with developmental coordination disorder, and instrument validation indicates that the PACS is useful in providing a profile of a child's activity pattern (MANDICH et al., 2004) .

Since its introduction, a number of studies about children's participation in activities have appeared citing the PACS. A study by Chien et al. (2014a) reported on the PACS relative the ICF. They found that the items in the PACS cover most of the nine ICF domains (CHIEN et al., 2014a) and are related either to participation or to activity. In another 
study, Chien et al. (2014b) conducted a systematic review to identify measures of participation outcomes related to hand use for 2 to 12 year-old children with disabilities. They found that $81.3 \%$ of PACS items are related to hand use, ranking it second among the nine tools examined from this perspective. In a study by Phelan and Kinsella (2014) the PACS was found to be a good measure to capture the individual activity profile of children with mobility disabilities. Calley et al. (2012) used the PACS as a measure of activity in their study with 38 children (19 with cerebral palsy). In a literature review undertaken by Tam, Teachman and Wright (2008) aiming to identify and compare the clinical utility of client-centred, individualised outcome measures for paediatric rehabilitation, the authors found five tools, including the PACS. However, no study reporting the psychometric qualities of PACS was identified in their research.

These citations, albeit limited in number, suggest that the PACS is a potentially useful tool for understanding children's activity participation. However, as the PACS was created in Canada, the pictures and activities that compose the PACS are all of Canadian children doing activities relevant to that context. This begs the questions of its usefulness within other contexts. In the case of the ACS, country-specific versions have been created; is it also necessary to create country-specific versions of the PACS?

As noted above, there are many factors that can influence participation. Thus, capturing and examining these differences is important to occupational therapists as it enhances our ability to enable our clients' full participation through activity. Unfortunately, little is known about the activity pattern of Brazilian children-typically developing or otherwise-nor are there any available assessments designed for Brazilian children that capture activity patterns. Accordingly, a study was undertaken to examine the usefulness of the PACS in the Brazilian context. Specifically we sought to a) determine the acceptability of the PACS to Brazilian children that is if Brazilian children between the ages of 5 to 14 would respond to the measure and if the PACS items were relevant to them, b) evaluate the PACS scores for the Brazilian participants in relation to sociodemographic variables: age, sex, parents' marital status, siblings, race, and parents' education on the activity pattern, and (c) identify what, if any, modifications should be made to the PACS to improve its applicability in the Brazilian context.

\section{Method}

\subsection{Research design}

This study used a descriptive cross-sectional design. A questionnaire was used to gather sociodemographic information, and the PACS was used to capture the activities in which children participate. As well, behavioural observations were used to judge the acceptability of the PACS to the children participating in the study.

\subsection{Participants}

Participants were recruited at a university hospital, before or after regular well-child care appointments. Children between ages 5 and 14 years were included. Only 3 participants presented with a specific disease or disorder; however, an analysis of outliers did not show any difference in activity participation for these three participants so all remained in the sample. The only exclusion criterion was children who were unable to see pictures due to a visual impairment as reported by their parents.

\subsection{Measures}

\subsubsection{Paediatric Activity Card Sort (PACS)}

The PACS was created as a tool for capturing the activity patterns of 5 to 14 year-olds. The PACS uses 75 cards each of which contains a photograph of a child engaging in an activity with the name of the activity written under it. The cards comprise four categories: personal care, school/productivity, hobbies/social activities, and sports. During this study in a quiet room, seated at a table, as per the manual instructions, each participant, with the support of a parent or guardian, was asked to look at each picture and indicate 'yes, I do this activity' or 'no, I do not do this activity' (MANDICH et al., 2004). For each activity, the participant was asked "Have you participated in this activity in the past year?". The PACS allows the therapist to ask about activities done daily, weekly, monthly or yearly, however in order to respond the objectives of this study, we use all the activities that the children have done in the last year. As well, at the end of each of the four categories, the participants were encouraged to identify any other activities they did that were not on the cards.

The PACS is scored by adding up the number of Yes responses in each of the four categories and 
then dividing by the total number of items in the category. This calculation generates the percentage of total activities reported being done in each category. Overall activity repertoire scores can then be calculated by adding the total number of Yes responses and dividing it by the total number of activities. Final scores allow for the therapist to see the total number of occupations that a child reports doing in four distinct domains of occupation (i.e. Personal Care, School/Productivity, Hobbies, and Sports). The final profile depicts the child's current activity repertoire, which is expressed as a percentage based on overall participation.

As there is no Brazilian version of the PACS, for the purposes of this study we used the Canadian photographs and translated all text, verbal and written. Translations were completed by two independent translators fluent in Portuguese and English. Disagreements between the translations were discussed by the translators, and a pre-final version of a Brazilian PACS was created. Should the findings indicate the PACS is useful in the Brazilian context a more comprehensive approach to creating a Brazilian PACS will be undertaken; back translation and cultural adaptation will be informed by findings from this study (COSTER; MANCINI, 2015).

\subsubsection{Socio-demographic questionnaire}

The parent(s) or guardian(s) were asked to provide sociodemographic information: age, sex, school grade, presence and number of siblings, parents' highest education level attained, and medical conditions.

Behavioural Observations: During the evaluations, the children were observed for any signs of difficulty with the instructions or tasks required of them. The type and amount of explanations required were noted as were signs of enjoyment or distress in completing the PACS. Children were encouraged to respond all questions.

\subsection{Procedures}

Sixty-four participants (ages 5 to 14 years) present in the well-child care waiting room of the ambulatory sector of the hospital were invited to participate in this study by occupational therapy students. Potential participants who expressed interest received the information letter. Parents provided written consent, and the children assented to participate in the study. Three parents and one child who were approached did not agree to participate in the study.
Parents provided the information for the sociodemographic questionnaire. Children were evaluated with the PACS in a private room next to the waiting room. The data were collected over four day sat different time periods (mornings or afternoons).

Ethical approval for this study was obtained from hospital's research ethics board and the university's research ethics board.

\subsection{Data analysis}

The PACS scores were computed as per manual instructions and data were analysed through the Statistical Package for Social Science (SPSS - Version 20.0). Descriptive statistics were used to describe participant's demographics, participation in individual activities, and activities patterns. The PACS scores were examined for normality using the Shapiro-Wilk test. As the distribution was non-normal, non-parametric statistics were used for all further data analysis. Differences on the PACS total and categories scores between sex, race, and presence of siblings were assessed using the Mann-Whitney test. The Kruskal-Wallis test was used to compare statistical differences in PACS scores between parent's educational levels and marital status.

A chi-square test for independence was conducted to identify significant differences in the activity pattern between sex e sand presence of siblings in in the family. Finally, the correlations among age, number of siblings, and changes in the PACS score were evaluated using the Spearman correlation coefficient. A $p$ value of 0.05 was considered statistically significant for all analyses. Effect size interpretation was based on the criteria proposed by (COHEN, 1988), considering 0.1 as a small effect size, 0.3 as a moderate, and 0.5 as a large effect size.

\section{Results}

Sixty children participated in this study, 28 girls and 32 boys, with a mean age of $09.57(\mathrm{SD} \pm 3,03)$ years. All participants were enrolled in a school grade consistent with their age at the time of the study. Parents' mean age was $36.00(\mathrm{SD} \pm 6,06)$ years for mothers and $39.05(\mathrm{SD} \pm 8,26)$ years for fathers, with most of the parents declaring high school as the highest educational level attained. According to the sociodemographic questionnaires, most families were composed of married couples with at least two children, and $75 \%$ of participants self-identified as black (see Table 1). 
Table 1. Demographics and pediatric activity card sort score.

\begin{tabular}{lc}
\hline \multicolumn{1}{l}{ Sex } & $\mathrm{n}(\%)$ \\
$\quad$ Male & $32(53.3)$ \\
$\quad$ Female & $28(46.7)$ \\
Race & \\
$\quad$ Black & $45(75)$ \\
$\quad$ White & $15(25)$ \\
Parent's Marital Status & \\
$\quad$ Married & $43(71.7)$ \\
Divorced & $12(20)$ \\
Living together, unmarried & $4(6.7)$ \\
Widow & $1(1.7)$ \\
Siblings & \\
$\quad$ Yes & $53(88.3)$ \\
No & $7(11.7)$ \\
Number of Siblings & \\
1 & $21(35)$ \\
2 & $19(31.7)$ \\
3 & $10(16.7)$ \\
$>4$ & $3(5)$ \\
Parents Highest Education/ Degree & \\
No formal education & $9(15)$ \\
Elementary school & $3(5)$ \\
High school & $34(56.7)$ \\
College/bachelor & $14(23.3)$ \\
\hline & \\
\end{tabular}

\subsection{Acceptability of the PACS to Brazilian children}

All 60 participants completed the evaluation. At the beginning of the assessment, the children seemed to enjoy the PACS equally, with girls showing more interest than boys. However, after half of the PACS, some older children complained about the length of the evaluation.

None of the children had difficulties understanding the instructions and objectives of the PACS. For children requiring additional explanations, most only needed help with the first three items.

\subsection{Relevance of the PACS items: participation in activities}

There was a variable response across items and categories. PACS scores indicated that participants reported performing most of the activities described in the personal care category $(M=10.5$ of 11 ; 94.6\%); this category had the highest reported rates of participation with some activities reported as being done by $100 \%$ of the participants, such as sleeping, eating/drinking, and brushing teeth.
Lower rates of participation were reported for the school/productivity category $(M=9.9$ of $17 ; 58.6 \%)$ and the hobbies category $(M=20.6$ of $35 ; 58.9 \%)$. Participants reported the lowest rate of participation in sports activities $(M=1.8$ of $12 ; 15.1 \%)$. Total scores ranged from $32(42.7 \%)$ to $54(72.0 \%)$ activities, with a mean of 42.1 activities (57.3\%). Eleven activities had less than $10 \%$ of participation. Activities such as baseball, hockey, golf, football, and skiing were not reported by any participants (see Table 2).

\subsection{Relation to sociodemographic variables}

Chi-square test of independence showed significant differences between boys and girls in specific activities reported as being done: Playing videogames $\left(\chi^{2}=4.77 ; p=0.02\right)$, soccer $\left(\chi^{2}=4.19\right.$; $p=0.04)$ and climbing in trees $\left(\chi^{2}=5.61 ; p=0.01\right)$ were reported as being performed by the majority $(62.5 \%)$ of boys, while girls reported doing more babysitting $\left(\chi^{2}=5.61 ; p=0.01\right)$, creative writing $\left(\chi^{2}=5.9 ; p=0.01\right)$ and skipping $\left(\chi^{2}=6.43 ; p=0.01\right)$. A medium effect size ( $\mathrm{Phi}=0.3$ ) was observed when comparing participation in these activities between boys and girls. Differences were also observed when comparing the children with and without siblings; children without siblings reported doing less babysitting $\left(\chi^{2}=4.855 ; \mathrm{p}=0.04\right)$ and gardening $\left(\chi^{2}=5.28 ; p=0.03\right)$ when compared with children with siblings.

The Mann-Whitney test revealed significant differences for reported participation in school/productivity and sports activities between sex: Boys participated in more sports activities $(p=0.03)$ while girls participated in more school/ productivity type activities ( $p=0.04)$ (see Table 3 ). Although the results showed significant differences, both categories presented a small effect size $(r=0.2)$. No significant differences were observed when comparing participants according to race, number of siblings, parent's highest educational level attained, and marital status.

Significant correlations between age and PACS scores for personal care and school/productivity activities were observed using Spearman's correlation coefficient (see Table 4), with higher scores associated with increased age. Results indicated a moderate, positive correlation for age and personal care $(r h o=0.48 ; p<0.001)$ and a large, positive correlation between age and productivity $(r h o=0.55 ; p<0.001)$. 
Table 2. PACS Activities, by category, with the three highest and three lowest reported participation rates.

\begin{tabular}{|c|c|c|c|c|c|}
\hline Category & $\begin{array}{l}\text { Highest reported } \\
\text { activities }\end{array}$ & $\mathrm{n}(\%)$ & $\begin{array}{l}\text { Lowest reported } \\
\text { activities }\end{array}$ & n ( $\%)$ & $\begin{array}{c}\text { Overall number } \\
\text { of reported } \\
\text { activites }(\%)\end{array}$ \\
\hline
\end{tabular}

Personal care ca $^{\text {Pan }}$

School/

Productivity

$\begin{array}{clcc}\text { Bathing/Showering } & 60(100) & \text { Brushing hair } & 59(98.3) \\ \text { Going to the toilet } & 60(100) & \text { Tying shoes } & 52(86.7) \\ \text { Dressing } & 60(100) & \text { Making a sandwich } & 41(68.3)\end{array}$

10.01(94.6)
Organizing (backpack/ desk)
Doing mathematics
Cursive writing

Hobbies

Watching TV
Drawing/Colouring
Going to a place of
worship

Sports $^{b}$

Playing soccer
Running
Playing volleyball

Total

55

53

46

60

59

56

43

31

15

$\begin{array}{cc}\text { Vacuuming } & 5 \\ \text { Doing the laundry } & 9 \\ \text { Gardening/Doing yard } & 24 \\ \text { work } & \end{array}$

5

9

4

$20.6(58.9)$
Playing road hockey 1
Playing in the snow 3
Participating on student 5 council

$1.8(15.1)$

$\begin{array}{cl}\text { Playing football } & 0 \\ \text { Playing golf } & 0 \\ \text { Playing baseball } & 0\end{array}$

${ }^{a}$ Five additional personal care activities presented $100 \%$ of participation (Brushing teeth, eating/drinking, sleeping, washing face and washing hands); ${ }^{\mathrm{b}}$ Two others sports presented $0 \%$ participation (hockey and skiing).

Table 3. Sex Differences in pediatric activity card sort scores.

\begin{tabular}{lcc}
\hline \multicolumn{1}{c}{ Activity categories } & Boys mean (range); SD & Girls mean (range); SD \\
\hline Personal care & $10.4(9-11) ; 0.7$ & $10.7(9-11) ; 0.6$ \\
Productivity* & $9.2(2-15) 3.4$ & $10.9(1-17) ; 3.5$ \\
Hobbies & $20.2(14-28) ; 3.6$ & $21.1(15-28) ; 4.3$ \\
Sports* & $2.1(0-5) ; 1.1$ & $1.5(0-3) ; 0.9$ \\
Total & $42.1(32-54) ; 5.8$ & $43.8(31-53) ; 6.2$ \\
\hline
\end{tabular}

${ }^{*} p<0.05-$ Mann-Whitney Test.

Table 4. Spearman's correlation between age and PACS scores.

\begin{tabular}{lcccccc}
\multicolumn{1}{c}{ Category } & $\mathbf{1}$ & $\mathbf{2}$ & $\mathbf{3}$ & $\mathbf{4}$ & $\mathbf{5}$ & $\mathbf{6}$ \\
\hline 1. Age & - & 0.21 & $0.48^{* *}$ & $0.55^{* *}$ & -0.23 & 0.06 \\
2. PACS total score & & - & $0.28^{*}$ & $0.66^{* *}$ & $0.76^{* *}$ & $0.49^{* *}$ \\
3. Personal care & & & - & $0.43^{* *}$ & -0.49 & 0.10 \\
4. School/productivity & & & & - & 0.10 & 0.11 \\
5. Hobbies & & & & & - & $0.37^{* *}$ \\
6. Sports & & & & & - \\
\hline${ }^{*} p<0.05 ; * * p<0.001$. & & & & &
\end{tabular}

\subsection{Modifications to be made for the Brazilian context}

Of all the 75 activities that compose the PACS, only three required additional information to be understood by the children. Playing Frisbee ${ }^{\circledR}$ and playing with Lego ${ }^{\circledR}$ were understood by all children after explanation. The activity participating on student council was not understood by the majority of Brazilian children; however, five participants did report participating in this activity.

After responding to all the PACS cards within a category, the participants were asked about their participation in others activities. In total, 22 other 
activities were identified, some with very high frequency. Fingernail care was the most cited activity in the personal care category of the additional activities. In the category school/productivity, four (6.7\%) older children reported cooking as an activity. Fourteen new activities were identified in the hobbies category, with playing tag being the most frequent (28.4\%). Handball, capoeira, and athletics were sports activities named by participants (see Table 5).

\section{Discussion}

In this study we investigated the usefulness of the PACS in the Brazilian context with a view to evaluating its potential as a tool for Brazilian pediatric occupational therapists. Our results indicated that the tool was readily acceptable to Brazilian 5 to 14 year olds with the majority of the items having relevance to them. However, items not included in the PACS were missing that were common among the Brazilian participants.

Table 5. Frequency and percentage of other activities identified, by category.

\begin{tabular}{lc}
\hline \multicolumn{1}{c}{ Otheractivities identified } & $\mathrm{n}(\%)$ \\
\hline Personal care & \\
Doing manicure & $14(23.3)$ \\
Blow drying/styling hair & $9(15)$ \\
Putting on make-up & $2(2.3)$ \\
School/Productivity & \\
Cooking & $4(6.7)$ \\
Washing bathroom & $3(5)$ \\
Ironing & $1(1.7)$ \\
Hobbies & \\
Playing tag & $17(28.4)$ \\
Playing dodgeball & $16(26.7)$ \\
Playing with doll & $13(21.7)$ \\
Playing hide and seek & $11(18.3)$ \\
Playing with kite & $9(15)$ \\
Skating & $6(10)$ \\
Playing table tennis & $6(10)$ \\
Playing marbles & $5(8.3)$ \\
Playing with toy cars & $5(8.3)$ \\
Playing games on cellphone/ & $5(8.3)$ \\
tablet & \\
Dancing & $4(6.7)$ \\
Playing foosball & $2(3.3)$ \\
Fishing & $2(3.3)$ \\
Playing peteca & $2(3.3)$ \\
Sports & \\
Handball & $7(11.6)$ \\
Capoeira & $3(5)$ \\
Athletics & $1(1.7)$ \\
Total number of other activities & 22 \\
\hline &
\end{tabular}

The highest participation levels were reported for the personal care activities of the PACS, while the lowest were reported for the sports activities, with moderate participation in school/productivity activities and hobbies. The high report of participation inactivity related to personal care seems appropriate given the ages of the participants (5 to 14 years old). According to Can Child (LAW et al., 2013), an internationally referenced source on child development, by 5 years of age, most children can brush their teeth, brush their hair, and dress, and by 7 to 8 years of age, generally children are proficient with most fine motor skills, such as tying shoes, with the ability to perform most daily life activities by themselves. Further, these results are in keeping with the data presented in the PACS manual (MANDICH et al., 2004) and those from a study by Calley et al. (2012) using the PACS, that showed Australian children ages 5 to 12 years, participated in $90.47 \%$ of the activities related to personal care.

There was a moderate participation rate reported by the Brazilian participants in activities related to school/productivity, which is less than presented in the PACS manual $(72,50 \%)$ (MANDICH et al., 2004). However, it is similar to the data reported by Calley et al. (2012), who found a participation rate of approximately $62 \%$. The moderate rate among the Brazilian participants seems appropriate and related to the educational system in Brazil, as schooling is mandatory through childhood and mid-adolescence and the mean time spent at school is around 4 to $5 \mathrm{hrs}$ per day (CAVALIERE, 2007).

The lowest reported school/productivity items among the Brazilian participants were those that could be considered chores (i.e., vacuuming, doing the laundry, gardening/yard work). However, three new chores were identified by Brazilian children: cooking, washing bathroom and ironing. Larson and Verma (1999) showed that participation in chores changes according to attendance at school, technology, and culture. Participation in chores tends to decrease when children attend school and within creased availability of technology; however, it tends to increase in countries that place greater value on being self-sufficient. For example, American parents report assigning chores to their children primarily because they believe that this helps to develop a child's individual sense of responsibility (LARSON; VERMA, 1999).

All of the participants reported doing at least one hobby. The mean percentage of Brazilian children's participation in hobby activities was $58.9 \%$. Data presented by the PACS manual (MANDICH et al., 2004) and by Calley et al. (2012) showed higher 
participation in hobby activities when compared with our results, $76.9 \%$ and $73.0 \%$, respectively. The most frequent hobbies in our study were sedentary activities, such as watching TV and drawing, similar to findings in other studies (FERRAR et al., 2013). According to Gorely et al. (2007), young people engage in a variety of leisure time activities; however, the majority are sedentary.

The Brazilian children presented a participation rate of $15.1 \%$ in sports activities. The PACS manual showed a participation rate of $67.2 \%$, while the Calley et al. (2012) study reported a participation rate of 39.9\%. These are substantially higher participation when compared with our results. The lack of children's participation in sports activities was also observed in another Brazilian study. Gonçalves et al. (2007) found a prevalence of sedentary lifestyle among $48.7 \%$ of 2181 boys and $67.5 \%$ of 2259 girls. They observed restricted participation due mostly to sociocultural factors, with parents prioritizing the participation of children in school and learning activities (GONÇALVES et al., 2007).

A recent study undertaken by the Brazilian government described the sports habits and preferences, as well the age of participation and quitclaim of the Brazilian population (BRASIL, 2015). The probabilistic sample comprised 8902 participants ages 15 to 75 years from across the country. The results showed that more than $45 \%$ of the participants did not practice any sport or physical activity. Only $6.8 \%$ of participants started to do a sport before 5 years. Most participants (37.9\%) started to do a sport activity between ages 6 and 10, and $31.4 \%$ between ages 11 and 14 years-old. The most common reason for not participating in any sport activity was lack of time, reported by $69.8 \%$. Soccer was the preferred sport, chosen by $42,7 \%$ of the participants. Walking (8.4\%) and volleyball (8.2\%) were the next most frequent. The participants reported a total of 29 sports/physical activities. Although reporting a sedentary rate of $45.9 \%$, this research showed that $54.1 \%$ of the participants do some sport or physical activity; a finding inconsistent with those observed in our study. The difference between the type of sports presented in the PACS and the Brazilian context may explain our findings.

Our study showed differences in participation patterns among boys and girls related to specific activities and for activity categories. Girls participated in more activities in the school/productivity category. No study using the PACS analyzed the difference in participation among sex. Whiting and Edwards (1988) analysed data from six different cultures and found that girls ages 4 to 10 years spent more time doing chores than boys, which is consistent with our study. Jarus et al. (2010) examined the differences in participation patterns between Israeli boys and girls. The results revealed a significant difference between sexes, where the girls had a higher level of participation in skill-based and informal activities, while boys had a higher level of participation in physical activities.

Molinuevo et al. (2010) found that it was more common for girls to participate in dance, workshops, and music than boys. However, they found that in sports, the tendency was reversed, with considerably more boys (83.37\%) than girls (59.11\%) participating. Our results were consistent, with boys participating in more sports, especially soccer. The Brazilian children in this study performed a mean of 1.8 (range 0 to 5) of the sports presented on the PACS with $71.7 \%$ of participants stating that they played soccer. In Brazil, soccer is a sport in which boys participate more than girls (FRANZINI, 2005), which explains the difference between sex for our sample.

Although the effect size was small, children with siblings participated in more activities related to school/productivity. No study using the PACS analysed the presence of siblings. Family structure, number of siblings, and birth order seems to affect participation, independence, creativity, and school performance; however, the findings are inconclusive and controversial (STEELMAN et al., 2002). No significant association was found between the number of siblings and participation in activities in our study.

Participation in activities tends to increase with age (LARSON; VERMA, 1999). Our study found that older children performed more activities related to personal care and school/productivity than younger children. Although the available studies using the PACS did not described the results according the age, the research conducted by Jarus et al. (2010) also found increased participation across age groups with a decline in oldest groups (12 to 18 years). However, they found an increase in social activities, in contrast to our findings that showed increase in participation in activities related to personal care and productivity.

Sociodemographic factors did not correlate with participation in activities, which contradicts the results presented by Shi and Yi (2014) in Taiwan, who found that afterschool activity is a class-differentiated phenomenon. A study conducted with 109 Brazilian parents did not find a direct association between socioeconomics factors and children participation 
in chores (DRUMMOND, 2014). No study using the PACS analysed the sociodemographic data.

Our data are congruent with the ICF model, which indicates that participation in activities are influenced by context (WORLD..., 2001). While many of the PACS activities appear to have relevance in the Brazilian context, some had a low participation rate. No Brazilian children participated in five of the sports on the PACS, and less than $10 \%$ participated in two of the rest. For hobbies, three activities had less than a $10 \%$ reported participation rate, and one activity related to school/productivity had less than $10 \%$ participation. From the 75 PACS activities, 11 had less than $10 \%$ of participation, which questions the applicability of the PACS to Brazilian children. As well, a number of activities were added.

Most additional activities involved outdoor play or games that occur in the streets and neighbourhoods of Brazil. Playing peteca and capoeira are historically linked to Brazilian context, as peteca originated from Indigenous peoples and capoeira from created by West Africans descendants. In contrast, winter sports, such as hockey and skiing, have evolved within the Canadian context due to the favourable climate for such activities. Further research is required to deepen the understanding of the occupational repertoire differences between Brazil and Canada.

Taken together the results of our study suggest that the pattern of reported activities and their associations seem to reflect the Brazilian context and that the PACS may have relevance for the Brazilian context. However, the items on the PACS would need amendment, and a Brazilian PACS would need to be created for the Brazilian context.

\subsection{Limitations}

This study was conducted at a university hospital and used a convenience sample of children attending a well-childcare appointment. The generalization of the results is limited due to the sampling size and methods. The participants were recruited from a specific hospital, which attends to a specific population profile. The small sample size did not allow for the use of regression models to investigate the influence of multiple variables on the outcome. The moderate effect sizes obtained from the statistical analysis also suggests that caution should be used when generalizing the results from this study. However, given the paucity of research about activity participation in Brazil, our results provide first findings. Studies with larger samples are required, as well as the analysis of more variables related to culture, the environment, time use, and family values.

\section{Conclusion}

The PACS was created as a means for assessing 5 to 14 year-old children's activity participation. Created in Canada, the PACS reflects the activities in which Canadian children may participate, which may present a different activity pattern. Coster and Mancini (2015) affirm that if an instrument contains many items that refer to daily activities or use of objects and equipment that are not common in the translation culture, doubt may be raised as to its cross-cultural relevance. Some PACS activities, specially related to sports and hobbies, did not seem to be a part of Brazilian children's activity repertoire. However, in general, the PACS seem to be a useful tool, suggesting the potential usefulness of a Brazilian PACS. Further, the findings provided preliminary information regarding the activities of Brazilian children; thus, our results can contribute to the creation of a new cross-cultural measurement tool for the Brazilian population. Such an instrument will supporter habilitation services when working with parents and their children, enabling them to identify possible challenges to activity participation.

\section{References}

BAUM, C. M.; EDWARDS, D. ACS: activity card sort: test manual. St Louis: Washington University School of Medicine, 2001.

BRASIL. Ministério do Esporte. A prática de esporte no Brasil: diagnóstico nacional do esporte. Brasília, 2015.

CALLEY, A. et al. A comparison of activity, participation and quality of life in children with and without spastic diplegia cerebral palsy. Disability and Rehabilitation, Oxford, v. 34, n. 15, p. 1306-1310, 2012.

CAVALIERE, A. M. Tempo de escola e qualidade na educação pública. Educação e Sociedade, Campinas, v. 28, n. 100, p. 1015-1035, 2007.

CHEUNG, P. P. Association of after-school physical activity levels and organized physical activity participation in Hong Kong children. European Physical Education Review, Cheshire, v. 18, n. 2, p. 182-190, 2012.

CHIEN, C. W. et al. Comparative Content Review of Children's Participation Measures Using the International Classification of Functioning, Disability and Health-Children and Youth. Archives of Physical Medicine and Rehabilitation, Philadelphia, v. 95, n. 1, p. 141152, $2014 \mathrm{a}$.

CHIEN, C. W. et al. Measures of participation outcomes related to hand use for 2-to 12-year-old children 
with disabilities: a systematic review. Child: Care, Health and Development, Oxford, v. 40, n. 4, p. 458-471, 2014b.

COHEN, J. W. Statistical power analysis for the behavioral sciences. Hillsdale: Lawrence Erlbaum Associates, Mahwah, 1988.

COSTER, W. J.; MANCINI, M. C. Recomendaçôes para a tradução e adaptação transcultural de instrumentos para a pesquisa e a prática em Terapia Ocupacional. Revista de Terapia Ocupacional da Universidade de São Paulo, São Paulo, v. 26, n. 1, p. 50-57, 2015.

DAVIS, J.; POLATAJKO, H. Occupational Development. In: RODGER, S.; ZIVIANI, J. (Org.). Оссираtional therapy with children: understanding children's occupations and enabling participation. Oxford: Blackwell Science Publishers, 2006. p. 136-154.

DRUMMOND, A. F. Participação de crianças e de adolescentes nas tarefas domésticas. 2014. 125 f. Tese (Doutorado em Ciências da Reabilitação) - Universidade Federal de Minas Gerias, Belo Horizonte, 2014.

FERRAR, K. et al. Adolescent time use clusters: a systematic review. Journal Adolesc Health, Oakbrook Terrace, v. 52, n. 3, p. 259-270, 2013.

FRANZINI, F. Futebol é "coisa para macho"?: Pequeno esboço para uma história das mulheres no país do futebol. Revista Brasileira de História, São Paulo, v. 25, n. 50, p. 315-328, 2005.

FREDRICKS, J. A.; SIMPKINS, S. D. Promoting positive youth development through organized after-school activities: taking a closer look at participation of ethnic minority youth. Child Development Perspectives, Ann Arbor, v. 6, n. 3, p. 280-287, 2012.

GONÇALVES, H. et al. Fatores socioculturais e nível de atividade física no início da adolescência. Revista Panamericana de Salud Pública, Washington, v. 22, n. 4, p. 246-253, 2007.

GORELY, T. et al. Patterns of sedentary behaviour and physical activity among adolescents in the United Kingdom: Project STIL. Journal of Behavioral Medicine, New York, v. 30, n. 6, p. 521-31, 2007.

JARUS, T. et al. Childhood participation in after-school activities: what is to be expected? The British Journal of Occupational Therapy, London, v. 73, n. 8, p. 344-350, 2010.

LARSON, R. W.; VERMA, S. How children and adolescents spend time across the world: work, play, and developmental opportunities. Psychological Bulletin, Washington, v. 125, n. 6, p. 701-736, 1999.

LAW, M. et al. Participation in the home environment among children and youth with and without disabilities. The British Journal of Occupational Therapy, London, v. 76, n. 2, p. 58-66, 2013.

LAW, M. Participation in the occupations of everyday life. American Journal of Occupational Therapy, Bethesda, v. 56, n. 6, p. 640-649, 2002.
LAW, M.; STEINWENDER, S.; LECLAIR, L. Occupation, health and well-being. Canadian Journal of $O c$ cupational Therapy, Ottawa, v. 65, n. 2, p. 81-91, 1998.

MANDICH, A. et al. The Pediatric Activity Card Sort (PACS). Ottawa: Canadian Occupational Therapy Association, 2004.

MANDICH, A.; RODGER, S. A. Doing, being and becoming: Their importance to children. In: RODGER, S.; ZIVIANI, J. (Org.). Occupational therapy with children: understanding children's occupations and enabling participation. Oxford: Blackwell, 2006. p. 115-135.

MOLINUEVO, B. et al. Participation in extracurricular activities and emotional and behavioral adjustment in middle childhood in Spanish boys and girls. Journal of Community Psychology, Hoboken, v. 38, n. 7, p. 842 $857,2010$.

PHELAN, S. K.; KINSELLA, E. A. Occupation and identity: perspectives of children with disabilities and their parents. Journal of Occupational Science, North Terrace, v. 21, n. 3, p. 334-356, 2014.

POLATAJKO, H. J. et al. Meeting the responsibility that comes with the privilege: introducing a taxonomic code for understanding occupation. Canadia Journal Occupational Therapy, Ottawa, v. 71, n. 5, p. 261-268, 2004.

SHARP, E. H. et al. Breadth of participation in organized and unstructured leisure activities over time and rural adolescents' functioning. Journal Youth Adolesc, New York, v. 44, n. 1, p. 62-76, 2015.

SHIH, Y. P.; YI, C. C. Cultivating the difference: social class, parental values, cultural capital and children's afterschool activities in Taiwan. Journal of Comparative Family Studies, Calgari, v. 45, n. 1, p. 55-76, 2014.

STEELMAN, L. C. et al. Reconsidering the effects of sibling configuration: Recent advances and challenges. Annual Review of Sociology, Palo Alto, v. 28, p. 243-269, 2002.

TAM, C.; TEACHMAN, G.; WRIGHT, V. Paediatric application of individualised client-centred outcome measures: a literature review. The British Journal of Occupational Therapy, London, v. 71, n. 7, p. 286-296, 2008.

TONKIN, B. L. et al. The participation of children and youth with disabilities in activities outside of school: a scoping review: Étude de délimitation de l'étendue de la participation des enfants et des jeunes handicapés à des activités en dehors du contexte scolaire. Canadian Journal of Occupational Therapy, Ottawa, v. 17, p. 1-11, 2014.

WEISNER, T. S. Ecocultural understanding of children's developmental pathways. Human development, New York, v. 45, n. 4, p. 275-281, 2002.

WHITING, B.; EDWARDS, C. P. A cross-cultural analysis of sex differences in the behavior of children aged 3 through 11. Journal of Social Psychology, Linconl, v. 91 , n. 2, p. 171-188, 1988. 
WISEMAN, J. O.; DAVIS, J. A.; POLATAJKO, H. J. Occupational development: towards an understanding of children's doing. Journal of Occupational Science, Nowra, v. 12, n. 1, p. 26-35, 2005.
WORLD HEALTH ORGANIZATION - WHO. International Classification of Functioning, Disability and Health (ICF). Geneva, 2001. Available from: <http://www.who. int/classifications/icf/en/>. Access on: 01 aug. 2015.

\section{Author's Contributions}

Tatiana Barcelos Pontes, Pedro Henrique Tavares Queiroz de Almeida: Conception and design of study; data analysis, and interpretation. Writing and critical review of the manuscript. Jane Davis, Helene Polatajko: Conception and design of study. Critical review of the manuscript. Bruna Mesquita Silva, Jaqueline Gonçalves Sousa: Data acquisition, writing and critical review of the manuscript. All the authors approved the final version of the manuscript.

\section{Funding Source}

The present study received financial support from the National Council for Scientific and Technological Development (Conselho Nacional de Desenvolvimento Científico e Tecnológico - CNPq), through the Scientific Initiation program and a post-doctoral scholarship via the Science Without Borders (Ciências Sem Fronteiras) program. 